\title{
The partial-reinforcement extinction effect in 4-5-day-old guinea pigs
}

\author{
WILLIAM A. DAILEY, MARK LINDNER, and ABRAM AMSEL \\ University of Texas, Austin, Texas
}

\begin{abstract}
The partial-reinforcement extinction effect was demonstrated at 4-5 days of age in the precocial guinea pig and was related to the appearance of this effect at 12-14 days in the altricial rat. We suggest that the maturity of the septohippocampal system at birth in the guinea pig, relative to the immaturity of this system in the rat, is a possible basis for this difference.
\end{abstract}

In recent years, we have been examining the ontogeny of a number of related reinforcement effects to which we have applied the term "paradoxical" (see Amsel \& Stanton, 1980, for a review). One of these effects, the one most thoroughly investigated over the past $\mathbf{4 0}$ years, is the partial-reinforcement extinction effect (PREE). This term describes the fact that instrumental training under a schedule of intermittent (often 50\%) reinforcement results in greater resistance to subsequent extinction than does training under continuous $(100 \%)$ reinforcement. The phenomenon is robust and, to our knowledge occurs in adults in every mammalian species that has been tested. Ontogenetic investigation of this effect in laboratory rats has shown that the PREE is not present in 11-day-old pups but can be shown to exist in pups 1 to 3 days older (Chen \& Amsel, 1980a, 1980b; Letz, Burdette, Gregg, Kittrell, \& Amsel, 1978).

Unlike the altricial rat, the precocial guinea pig is relatively mature at birth. Its brain and sensory systems function at or near adult levels (Tilney \& Kubie, 1931). The development that occurs in the first 3 weeks of life in the rat has already occurred in the guinea pig by the time of birth, and the guinea pig's neonatal brain is said to be roughly equivalent to the 40-50-day-old rat's brain (Dobbing \& Sands, 1970).

This early CNS maturity in the neonatal guinea pig is paralleled by behavior that in the rat has a much later development. In the guinea pig, but not in the rat, there is little variation in behavioral arousal from 5 to 100 days of age (Campbell \& Mabry, 1972), and there is no difference in the acquisition or retention of an escape or a passive-avoidance response between infancy ( 5 days old) and adulthood (100 days old) (Campbell, Misanin, White, Lytle, 1974). Spontaneous alternation, which is first displayed in the rat at about 27-28 days, appears 3 weeks earlier in the

This research was supported by Grant $\mathrm{MH}-30778$ from the National Institute of Mental Health. Requests for reprints should be sent to Abram Amsel, Department of Psychology, University of Texas, Austin, Texas 78712. guinea pig (Douglas, Peterson, \& Douglas, 1973). Lesions of the septohippocampal system appear to reduce or eliminate spontaneous alternation (e.g., Douglas \& Isaacson, 1964; Roberts, Dember, \& Brodwick, 1962), while lesions of amygdala, cingulate gyrus, and various cortical areas are ineffective in this regard (Douglas, Kowal, \& Clark, Note 1).

Virtually the same statements can be made for response persistence in extinction, including the PREE, which is reduced or eliminated in adult rats by lesions of the septum but not of the amygdala (Henke, 1974, 1977), by lesions of the hippocampus (Amsel, Glazer, Lakey, McCuller, \& Wong, 1973; Rawlins, Feldon, \& Gray, 1980), by blocking of the hippocampal theta rhythm by septal stimulation (Gray, Araujo-Silva, \& Quintao, 1972), and by administration of amobarbital (Gray \& Ball, 1970).

All of this suggests that the PREE that appears between Day 12 and Day 14 in the rat should occur much earlier in the guinea pig. We conducted an experiment to test this hypothesis.

\section{METHOD}

\section{Subjects}

The subjects were 16 4-day-old guinea pigs born in our laboratory to mothers obtained during the last month of pregnancy from the University's Animal Resource Center. Each experimental group contained no more than two subjects from the same litter, and each litter contributed at least one subject to each group. Each group was approximately counterbalanced for sex. Age was determined by checking for births every morning and evening and designating the day of birth as Day 0 . Litters were housed in $48 \times 48 \times$ $20 \mathrm{~cm}$ plastic cages that contained pine shavings and a continuous supply of tap water and Purina guinea pig food. The room was illuminated from 0800 to $2200 \mathrm{~h}$, and the pups were run during this part of the light-dark cycle.

\footnotetext{
Apparatus

The apparatus was a small Plexigias runway with a $13 \times 17.5$ $\times 10 \mathrm{~cm}$ startbox, a $32 \times 7.5 \times 10 \mathrm{~cm}$ alley, and a $17 \times 25 \times 10 \mathrm{~cm}$ goalbox. The startbox and goalbox had manually operated sliding doors made of opaque Plexiglas. An electric timer was activated by the raising of the startbox door and was stopped when the subject broke a photobeam at the entrance to the goalbox. This yielded a
} 
single running time measure. A fixed, top-to-bottom aluminum partition in the goalbox prevented the subject from seeing the contents of the food cup prior to having entered the goalbox. The food cup was a heavy glass evaporation dish $3 \mathrm{~cm}$ in diameter and $1.5 \mathrm{~cm}$ deep.

\section{Procedure}

The 16 animals in this experiment were run in squads of 2 to 4 , depending on litter size. A squad consisted of pups derived from the same litter, with at least one continuous reinforcement (CRF) and one partial reinforcement (PRF) subject in each squad. On Day 1, each subject received two 15-minm goalbox placements, one in the morning and one in the evening, along with several minutes of handling. Goalbox placement consisted of placing each pup and a reward-filled food cup into the goalbox. After $15 \mathrm{~min}$, the subject was returned to its litter, and after the last subject in the squad had been returned to the litter, a food cup filled with the reward was placed in the home cage. Throughout the procedure, reward consisted of chilled, pureed lettuce. On Day 2, the same procedure was followed, except that the duration of the placements was increased from 15 to $30 \mathrm{~min}$. Early in the morning on Day 3, each pup received a 45-min goalbox placement as before, at the conclusion of which the pup was placed in an individual plastic deprivation cage, $18 \times 28 \times 13 \mathrm{~cm}$, lined with pine shavings. The subject was then deprived of food and water for $24 \mathrm{~h}$. On the morning of Day 4, after $24 \mathrm{~h}$ of deprivation, and at the start of each subsequent session, the subjects were removed from their deprivation cages and transferred to individual Plexiglas intertrial interval (ITI) boxes, $11.5 \times 11.5 \times 17 \mathrm{~cm}$, located adjacent to the runway.

Training was conducted over 2 days, with four acquisition sessions of five trials each per day, followed by one session on the 2 nd day that consisted of three interpolated CRF trials followed directly by 40 extinction trials. The interval between sessions on each day was $90 \mathrm{~min}$. During acquisition, the CRF group received 30-sec access to the pireed lettuce reward on each trial, whereas the PRF group received 30-sec access to the lettuce on $50 \%$ of the trials and 30-sec access to an empty food dish on $50 \%$ of the trials according to the schedule RRNNRRNRNNRRRNNNRNNRNN RRNNRRRNNRNRRRNNRN ( $R=$ reward, $\mathbf{N}=$ nonreward). The subjects in each squad were run in rotation, and running order was randomized for each session.

At the start of Session 1 only, the subjects were given three priming trials, each of which consisted of placing the pup at the end of the alley nearest the goalbox and allowing it to enter the goalbox and receive 30 -sec access to reward. The priming trials, as well as all subsequent trials, were conducted with a 3 -min ITI. Following the last trial of a session, each pup was returned to its deprivation cage. The CRF subjects each received a very small amount of pureed lettuce, whereas the PRF subjects each received enough pureed lettuce to equate the CRF and PRF groups for total lettuce intake. Following the last session of Day 1 (Session 4), all subjects had access to water in their deprivation cages until the start of Session 5 on Day 2.

Ninety minutes after the end of Session 8 on Day 2, the subjects in both groups were once again placed in the ITI boxes and given three CRF trials. This interpolated CRF phase was continuous with the beginning of extinction. Extinction trials were run in a single session of 40 trials and were identical to acquisition trials except that they involved 30-sec exposure to an empty food cup on all trials. In the event that a subject did not break the photobeam within $60 \mathrm{sec}$, that subject was manually moved into the goalbox, and a response time of $60 \mathrm{sec}$ was recorded. The running response was considered to be extinguished after three consecutive 60 $\mathrm{sec}$ trials, and a score of $60 \mathrm{sec}$ was assigned thereafter.

\section{RESULTS}

The results of this experiment are shown in Figure 1 , which plots mean running times for the CRF

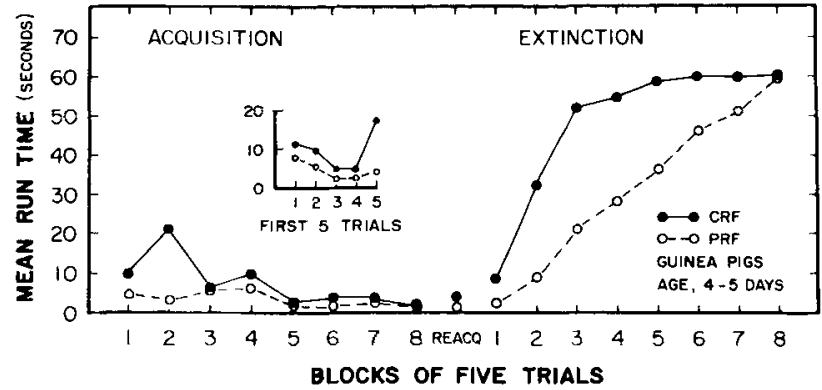

Figure 1. Acquisition, reacquisition, and extinction of a running response in 4-5-day-old guinea pigs. Insert presents data of first trials separately.

and PRF groups during acquisition, the interpolated CRF phase, and extinction. The insert shows mean trial-by-trial running speeds over the first five trials, to describe acquisition early in training.

That the animals acquired the running response is reflected in a significant main effect of blocks $[F(7,98)$ $=2.91, p=.008]$. The difference in running times across acquisition for the two groups fell short of significance $[F(1,14)=3.63, p=.078]$, as did the groups $\times$ blocks interaction $[F(7,98)=1.85, p=.086]$. This suggestion of lower running times (faster running) in the PRF group, particularly in the first 15 trials, may be due to heightened emotionality in the PRF group (see Discussion).

The two groups did not differ significantly across the three interpolated CRF trials, as shown by the absence of a main effect of groups $[F(1,14)=2.10$, $\mathrm{p}=.169]$ and the absence of a groups $x$ trials interaction $[\mathrm{F}(2,28)=.79, \mathrm{p}=.465]$.

That the running times increased across extinction is shown by a main effect of blocks $[F(7,98)=47.92$, $\mathrm{p}<.0001]$. The difference between the two groups was significant, producing a main effect of groups $[F(1,14)=8.95, p<.01]$ and a significant groups $X$ blocks interaction $[F(7,98)=3.90, p<.001]$.

\section{DISCUSSION}

Guinea pigs trained and tested at 4-5 days of age show a clear PREE despite interpolated CRF trials between training and extinction. In the rat, the effect first appears between 12 and 14 days. We have proposed elsewhere (Amsel \& Stanton, 1980) that the emergence of the PREE and other paradoxical reinforcement effects depends upon some level of functional maturity in the septohippocampal system. The present result is consistent with this position insofar as, in the rat but not in the guinea pig, (1) the hippocampus is not functionally mature until at least 30 days of age - the number of granule cells in the dentate gyrus shows its greatest development in the 2nd week of life and increases sixfold by adulthood (Altman \& Das, 1965), and (2) the theta rhythm that has been linked to the PREE in the rat (Gray et al., 
1972) is first seen in the rat at 12 days of age but is present in the guinea pig from birth (Gillespie, 1974).

A caveat is necessary here. Guinea pigs are notoriously difficult to train, and our infant guinea pig preparation compounded this problem. We were, therefore, forced to devise special procedures to get these infants to run, so there are a large number of specific procedural factors that differ between our infant guinea pigs and infant rats, which are also not easy to train. One obvious factor is the nature of the reward. Our operating principle with infants of both species has been to devise procedures of deprivation, reward, and pretraining that will get these animals to approach the goal consistently on the first few training trials. In the case of the infant rat, as in the goalbox placements in the guinea pig, for example, we always give "priming" trials in which the pup is placed directly on the nipple of the anesthetized dam in the goalbox to facilitate later training to approach.

In addition to the reported running time differences, we also have observed a striking difference in the vocalizations in the CRF and PRF groups, which, unfortunately, we did not anticipate and record. Specifically, early in acquisition the guinea pigs in the PRF group would squeak repeatedly upon encountering the empty food dish on the early nonreward trials. (This vocalization early in PRF acqusition on nonreward trials was apparently an indicant of frustration related to the strong reward expectancy generated by the many goalbox placements and priming trials that were required to get the guinea pig pups to run in the alley. And this heightened frustrative emotionality might have been the cause of the more vigorous performance in the PRF than in the CRF subjects early in training.) The vocalization gradually diminished, so that by the end of acquisition, the PRF animals were quiet on both reward and nonreward trials. In contrast, the CRF subjects were quiet throughout acquisition. In extinction, whereas the PRF subjects were relatively quiet, the CRF subjects began to vocalize vigorously in the goalbox.

These observations parallel findings of two earlier experiments. In one, involving the precocial domestic chick (Amsel, Wong, \& Scull, 1971), distress calling recorded in the goalbox was greater early in acquisition in the PRF than in the CRF groups, declined to zero in both groups by the end of training, and was intense early in extinction in the CRF but not the PRF group. In another, involving 11-day-old rats (Amsel, Radek, Graham, \& Letz, 1977), ultrasounding that had virtually disappeared during the acquisition of an approach-to-dam response increased approximately 20 -fold over the course of extinction. The pattern of vocalization in all of these experiments is thought to reflect the emotional response of primary frustration to nonreward, which is either not present in CRF or is reduced in PRF acquisition and reap- pears in extinction, particularly under CRF conditions.

\section{REFERENCE NOTE}

1. Douglas, R. J., Kowal, D., \& Clark, G. Spontaneous alternation and the brain. Paper presented at the meeting of the Western Psychological Association, San Diego, May 1968.

\section{REFERENCES}

Altman, J., \& Das, G. D. Autoradiographic and histological evidence of postnatal hippocampal neurogenesis in rats. Journal of Comparative Neuology, 1965, 124, 319-336.

Amsel, A., Glazer, H., Lakey, J. R., McCullen, R., \& Wong, P. T. P. Introduction of acoustic stimulation during acquisition and resistance to extinction in the normal and hippocampally damaged rat. Journal of Comparative and Physiological Psychology, 1973, 84, 176-186.

Amsel, A., RAdek, C. C., Graham, M., \& Letz, R. Ultrasound emission in infant rats as an indicant of arousal during appetitive learning and extinction. Science, 1977, 197, 786-788.

Amsel, A., \& Stanton, M. Ontogeny and phylogeny of paradoxical reward effects. In J. S. Rosenblatt, R. A. Hinde, C. Beer, \& M. Busnel (Eds.), Advances in the study of behavior. New York: Academic Press, 1980.

Amse l, A., Wong, P. T. P., \& Scull, J. Transfer of persistence in the domestic chick: Imprinting, punishment, and resistance to extinction of a food-reward running response. Psychonomic Science, 1971, 25, 174-176.

Campbell, B. A., \& MABry, P. D. Ontogeny of behavioral arousal: A comparative study. Journal of Comparative and Physiological Psychology, 1972, 81, 317-379.

Campeele, B. A., Misanin, J. R., White, B. C., \& Lytle, L. D. Species differences in ontogeny of memory: Indirect support for neural maturation as a determinant of forgetting. Journal of Comparative and Physiological Psychology, 1974, 87, 193-202.

Chen, J.-S., \& Amsel, A. Learned persistence at 11-12 days but not at 10-11 days in infant rats. Developmental Psychobiology, $1980,13,481-491$. a

Chen, J.-S., \& Amsel, A. Retention under changed-reward conditions of persistence learned by infant rats. Developmental Psychobiology, 1980, 13, 469-480. b

DobBing, J., \& SANDS, J. Growth and development of the brain and spinal cord of the guinea pig. Brain Research, 1970, 17, 115-123.

Dovglas, R. J., \& Isancson, R. L. Hippocampal lesions and activity. Psychonomic Science, 1964, 1, 187-188.

Douglas, R. J., Peterson, J. J., \& Douglas, D. P. The ontogeny of a hippocampus-dependent response in two rodent species. Behavioral Biology, 1973, 8, 27-37.

GILLESPIE, L. A. Ontogeny of hippocampal electrical activity and behavior in rat, rabbit, and guinea pig. Unpublished doctoral disseration, University of Western Ontario, 1974.

Gray, J. A., Araujo-Sirva, M. T., \& Quintao, L. Resistance to extinction after partial reinforcement training with blocking of the hippocampal theta rhythm by septal stimulation. Physiology \& Behavior, 1972, 8, 497-502.

Gray, J. A., \& BALL, G. C. Frequency-specific relation between hippocampal theta rhythm, behavior, and amobarbital action. Science, 1970, 168, 1246-1248.

Henke, P. G. Persistence of runway performance after septal lesions in rats. Journal of Comparative and Physiological Psychology, 1974, 86, 760-767.

Henke, P. G. Dissociation of the frustration effect and the partial reinforcement extinction effect after limbic lesions in rats. 
Journal of Comparative and Physiological Psychology, 1977, 91, 1032-1038.

Letz, R., Burdette, D. R., Gregg, B., Kittrell, E. M. W., \& AMSEL, A. Evidence for a transitional period for the development of persistence in infant rats. Journal of Comparative and Physiological Psychology, 1978, 92, 856-866.

Rawlins, J. N. P., Feldon, J., \& Gray, J. A. The effects of hippocampectomy and of fimbria section upon the partial reinforcement extinction effect in rats. Experimental Brain Research, $1980,38,273-283$.
Roberts, W. W., Dember, W. N., \& Brodwick, M. Alternation and exploration in rats with hippocampal lesions. Journal of Comparative and Physiological Psychology, 1962, 55, 695-700. Tilney, F., \& Kubie, L. S. Behavior in its relationship to the development of the brain. Bulletin of the Neurological Institute of New York, 1931, 1, 229-313.

(Manuscript received July 26, 1982;

revision accepted for publication January 24, 1983.) 